\title{
Tratamento Cirúrgico da Endocardite Infecciosa na Fase Aguda: Experiência de Três Anos
}

\author{
Iseu Affonso da COSTA*, Djalma Luiz FARACO*, Fábio SALLUM*, Aldo PESARINI ${ }^{\star *}$, Elson C. OLIVEIRA**, \\ Francisco Diniz Affonso da COSTA ${ }^{* \star}$, Álvaro B. SOEIRO***
}

COSTA, I. A.; FARACO, D. L.; SALlum, F.; PESARINI, A.; OliveIRA, E. C.; COSTA, F. D. A.; SOEIRO, A. B. - Tratamento cirúrgico da endocardite infecciosa na fase aguda: experiência de três anos. Rev. Bras. Cir. Cardiovasc., 2(2): 109-114, 1987.

RESUMO: O tratamento cirúrgico da endocardite na fase aguda vem-se impondo como o mais efetivo. em muitas circunstâncias clínicas. As contínuas modificaçōes nos aspectos clínicos, diagnósticos e bacteriológicos desta afecção tornam necessária permanente avaliação dos resultados, nas situaçōes concretas de atuação dos diversos grupos clínico-cirúrgicos. A definição de normas de conduta ante esta grave afecção tem-nos preocupado, ultimamente, por sua crescente participação em nossa prática clínica-cirúrgica. De novembro de 1983 a novembro de $1986,6,7 \%$ das substituiçóes valvares por nosso grupo cirúrgico deveram-se a endocardite ( 32 de 4,77 pacientes). A sede do processo infeccioso teve a seguinte distribuição: mitral 6 casos, aórtica 12 casos (um óbito), mitral e aórtica 6 casos (dois óbitos) prótese aórtica 4 casos (três óbitos), prótese mitral 2 casos (um óbito) mitral, aórtica e tricúspide 1 caso (um óbito) e parede do ventriculo esquerdo 1 caso. A idade variou entre 10 e 56 anos. Sete pacientes eram do sexo feminino e 24 do masculino. Todos os pacientes eram brancos. $\mathrm{A}$ análise dos achados anátomo-patológicos permitiu determinação de três grupos: no Grupo A, tivemos 11 operações por lesões valvares simples, consistentes basicamente de vegetaçōes infectadas. Todos os pacientes sobreviveram e obtiveram alta hospitalar. Nos 15 pacientes do Grupo B, havia acometimento multivalvar, ou lesões complicadas por mutilaçōes valvares extensas e/ou comunicações entre câmaras cardiacas; 5 pacientes faleceram. No Grupo C, houve 5 operaçōes por infecçōes em próteses, ocorrendo 4 óbitos. O prognóstico favorável dos pacientes operados com lesōes simples e o alto risco daqueles em que havia destruição tissular mais extensa e daqueles em que a endocardite se instalou em próteses, nos levam a defender o tratamento cirúrgico precoce das infecçōes valvares, em todos os casos em que não haja rápida resposta ao tratamento antibiótico.

DESCRITORES: endocardite infecciosa, cirurgia.

\section{INTRODUÇÃO}

O aparecimento de antibióticos bactericidas de amplo espectro iniciou nova fase no tratamento da endocardite bacteriana, aumentando, notavelmente, a possibilidade de cura.

Em 1965, WALLACE et alii ${ }^{16}$ publicaram o primeiro caso em que foi possível, com sucesso, substituir a valva

Trabalho realizado na Santa Casa de Curitiba, no Departamento de Cirurgia da Universidade Federal do Paraná e no Centro de Cardiologia Infantil do Paraná. Curitiba, PR, Brasil.

Apresentado ao 14: Congresso Nacional de Cirurgia Cardiaca. Salvador, BA, 27 e 28 de março, 1987.

- Da Santa Casa de Curitiba, do Departamento de Cirurgia da Universidade Federal do Paraná e do Centro de Cardiologia Infantil do Paraná.

- Da Santa Casa de Curitiba e do Centro de Cardiologia infantil do Paraná

... Do Departamento de Cirurgia da Universidade Federal do Paraná.

Endereço para separatas: Iseu A. Costa. Rua Carmelo Rangel, 816. 80420 Curitiba, PR, Brasil 
COSTA, I. A.: FARACO. D. L.: SALLUM, F.: PESARINI. A.: OlIVEIRA. E. C.: COSTA. F. D. A : SOEIRO. A. B. - Tratamento cirurgico da endocardite infecciosa na fase aguda: experiência de très anos. Rev. Bras. Cir. Cardiovas. 2(2): 109-114. 1987

aórtica, durante a fase aguda de infecção bacteriana, resistente ao tratamento antibiótico.

Subseqüentemente, o tratamento cirúrgico das lesōes valvares infectadas passou a ser aceito como a melhor alternativa, em determinadas situações, com surpreendente proporção de bons resultados $2,6,10,18$.

Assim, WILSON et alii ${ }^{18}$ analisaram as substituiçōes valvares, na Clínica Mayo, num total de 4310 pacientes, verificando mortalidades similares nos casos infectados $(14: 138=10 \%)$ e não infectados $(501: 4-238=12 \%)$.

No Brasil, Gallucci e colaboradores começaram a tratar cirurgicamente casos de endocardite aguda, desde 1969 , e, em 1979, relataram 47 pacientes, com $12,5 \%$ de mortalidade operatória e $75 \%$ de sobrevida em 5 anos (LEÃO et alii ${ }^{6}$ ).

Inúmeros outros relatos confirmam altos índices de sucesso na substituiçāo de valvas ativamente infectadas.

Entretanto, é necessário temperar o entusiasmo na indicação cirúrgica nas valvopatias infectadas, tendo em conta os vários fatores que influem no prognóstico, levar em conta variaçōes regionais e temporais, nas situações concretas de atuação de cada grupo cirúrgico, a mutabilidade dos agentes etiológicos e as características das populações de pacientes a serem tratados.

Aqui, como em muitas outras situações clínicas, a comparação pura e simples de resultados obtidos por grupos cirúrgicos diferentes, atuando em épocas e locais diversos, pode ser enganosa ${ }^{9.13}$.

Deste modo, cada grupo cirúrgico deve avaliar sua situação particular, no tempo e no espaço, para chegar a conclusões realistas sobre a melhor conduta aplicável na prática.

Em 1984, OLIVEIRA et alii ${ }^{12}$, no Hospital das Clínicas da Universidade Federal do Paraná, verificaram, nos anos de 1981 a 1983, 46 pacientes admitidos com diagnóstico de endocardite bacteriana, com a mortalidade global de $34,7 \%$.

A atitude terapêutica foi conservadora, como mostra o fato de apenas $8(17,4 \%)$ dos casos terem sido encaminhados à cirurgia.

A mortalidade hospitalar, neste subgrupo, foi de 4 casos $(50 \%)$.

Estes resultados nos levaram a defender conduta mais agressiva, com relação à endocardite aguda, seguindo a tendência de inúmeros Serviços cirúrgicos.

A mudança de atitude refletiu-se na conduta adotada no Hospital, resultando em maior porcentagem de casos encaminhados à operação, em fase mais precoce da doença.
De junho de 1983 a março de 1985,23 casos foram diagnosticados e 18, encaminhados à cirurgia, depois de um tempo relativamente curto de hospitalizaçâo.

Naquela data, analisamos 100 pacientes consecutivos, que receberam próteses cardiacas, verificando que $17 \%$ apresentavam lesōes infectadas.

A mortalidade hospitalar, nesta série, foi de $27,7 \%$.

Em apenas 5 pacientes encontramos lesões valvares simples, isto é, valvas integras, com vegetações infectadas. Nos restantes 12 pacientes, havia lesões complicadas por rotura valvar, abscessos de raiz aórtica, ou deiscência de próteses.

Para atualizar os dados de nossa experiência, revemos, no presente trabalho, os casos de endocardite aguda, tratados cirurgicamente na fase ativa, nos últimos 3 anos.

\section{MATERIAL E MÉTODOS}

Analisamos 32 pacientes operados na fase ativa de endocardite aguda em valvas, ou próteses valvulares, na Disciplina de Cirurgia Torácica e Cardiovascular do Hospital das Clínicas da Universidade Federal do Paraná, no Serviço de Cirurgia Cardiaca da Santa Casa de Curitiba e no Centro de Cardiologia Infantil do Paraná, no período de novembro de 1983 a novembro de 1986 .

A idade variou de 10 a 56 anos ( $m=29,2$ anos), sendo 8 pacientes femininos e 24 masculinos. Todos os pacientes eram brancos.

Neste periodo, foram realizadas 477 operações para substituição de uma ou mais valvas cardiacas, sendo, portanto, de $6,7 \%$ a proporção de casos operados na vigência de infecção bacteriana aguda.

O acometimento valvar e a respectiva mortalidade estão especificadas na Tabela 1.

TABELA 1

\begin{tabular}{lll}
\hline \multicolumn{1}{c}{ Sede } & $N$ & \\
\hline Mitral & 6 & - \\
\hline Aórtica & 12 & 1 \\
\hline Mitral + Aórtica & 6 & 2 \\
\hline Aórtica + Mitral + Tricúspide & 1 & 1 \\
\hline Prótese mitral & 2 & 1 \\
\hline Prótese aórtica & 4 & 3 \\
\hline Ventrículo Esquerdo & 1 & - \\
\hline Total & 32 & 8 (25\%) \\
\hline
\end{tabular}


COSTA, I. A.; FARACO, D. L.; SALLUM, F.: PESARINI, A.: OLIVEIRA, E. C.: COSTA. F. D. A.: SOEIRO. A. B. - Tratamento cirúrgico da endocardite infecciosa na fase aguda: experiència de três anos. Rev. Bras. Cir. Cardiovas. 2(2): 109-114. 1987

A análise dos achados anatomopatológicos transoperatórios permitiu distribuir os casos em três subgrupos (Tabela 2).

TABELA 2

\begin{tabular}{ccc}
\hline $\begin{array}{c}\text { A - Lesōes valvares simples } \\
\text { (vegetaçōes) }\end{array}$ & 11 & - \\
\hline $\begin{array}{c}\text { B- Lesōes valvares complicadas } \\
\text { (roturas, abscessos, fistulas) }\end{array}$ & 14 & 5 \\
\hline C - Próteses infectadas & 6 & 3 \\
\hline $\begin{array}{c}\text { D - Ventrículo esquerdo } \\
\text { (endomiocardiofibrose) }\end{array}$ & 1 & - \\
\hline Total & 32 & 8 \\
\hline
\end{tabular}

O estudo bacteriológico (hemoculturas, culturas do material das lesōes) mostrou variabilidade etiológica (Tabela 3).

TABELA 3

\begin{tabular}{|c|c|}
\hline Agente & $N$ \\
\hline Estreptococos & 7 \\
\hline Estafilococos & 5 \\
\hline Estafilo + estreptococos & 1 \\
\hline Bacilos gram-negativos & 7 \\
\hline Cocos gram-positivos & 1 \\
\hline Fungos & 2 \\
\hline Não determinados & 9 \\
\hline Total & 32 \\
\hline
\end{tabular}

A substituiçāo valvar foi realizada empregando-se as próteses indicadas na Tabela 4.

\section{DISCUSSÃO}

Em nossa prática, defendemos o tratamento cirúrgico das endocardites bacterianas agudas, desde que não se verifique nítida melhora com o tratamento antibiótico em 24-48 horas.

Em 1985, analisando a casuística clínica da Disciplina de Cirurgia Torácica e Cardiovascular do Hospital
TABELA 4

\begin{tabular}{ll}
\hline Próteses aórticas de disco & 10 \\
\hline Próteses aórticas de bola & 2 \\
\hline Próteses aórticas de pericárdio bovino & 1 \\
\hline Próteses mitrais de disco & 8 \\
\hline Próteses mitrais de pericárdio bovino & 6 \\
\hline Próteses mitrais de bola & 1 \\
\hline Próteses tricúspides de pericárdio bovino & 1 \\
\hline Total & 39 \\
\hline
\end{tabular}

das Clínicas da Universidade Federal do Paraná, encontramos elevada incidência (17\%) de casos infectados, no conjunto de substituições valvares efetuadas num período de 2 anos (junho de 1983 a maio de 1985).

A mortalidade foi de 5 , de 18 pacientes.

Ampliando o universo observado, estudamos a incidência de endocardites infecciosas agudas, dentre as substituiçōes valvares realizadas em três Serviços, nos quais nosso grupo cirúrgico atua (Hospital de Clínicas da Universidade Federal do Paraná, Santa Casa de Misericórdia de Curitiba e Centro de Cardiologia Infantil do Paraná).

Refletindo a composição sócio-econômica das populaçōes atendidas, observamos menor incidência de casos infectados do que na série do Hospital de Clínicas, embora fosse ainda elevada $(6,7 \%$, de 477 pacientes operados).

A análise da mortalidade operatória permitiu verificar marcada diferença nos subgrupos de lesões simples, lesōes complicadas e próteses infectadas.

Enquanto, para os pacientes operados com lesões simples, a mortalidade foi nula, nos casos em que havia extensão extravalvar, ou mutilação valvar, ou nos que apresentavam próteses infectadas, os resultados foram gravados com alta mortalidade (cinco óbitos, em 15 casos, e três óbitos, em 5 casos, respectivamente).

A localizaçāo do processo infeccioso também mostrou importância prognóstica: nas infecçōes isoladas de valva mitral (seis casos), não ocorreu óbito e, nos 12 pacientes aórticos, ocorreu um óbito. Tivemos, portanto, um óbito de 18 casos de lesōes valvares isoladas.

O acometimento multivalvar foi acompanhado de maior mortalidade: dois óbitos em 6 casos de acometi- 
COSTA. I. A.: FARACO. D. L.: SALLUM. F.: PESARINI, A.: OLIVEIRA. E. C.: COSTA. F. D. A.: SOEIRO. A. B. - Tratamento cirúrgico da endocardite infecciosa na fase aguda: experiência de três anos. Rev. Bras. Cir. Cardiovas. 2(2): 109-114. 1987.

mento mitro-aórtico e um óbito em caso de lesão mitroaorto-tricúspide.

A predominância da localização aórtica $(50 \%$ de nossos casos) em comparação com o mitral $(25 \%)$ e mitro-aórtica $(17,8 \%)$ está de acordo com o referido na literatura ${ }^{15}$.

Encontramos apenas 1 caso de acometimento da valva tricúspide $(3,1 \%)$. A incidência de infecções endocárdicas no coração direito varia, nas séries publicadas, com a proporção de toxicômanos na população atendi$\mathrm{da}^{4,13}$.

Entre nossos pacientes, apenas 1 era drogado, tendo apresentado endocardite aórtica, operada com sucesso.

As próteses infectadas levaram a alta letalidade operatória. Um óbito em 2 próteses mitrais infectadas e três em 4 próteses aórticas.

Maior letalidade nos casos de próteses infectadas em comparaçāo com as lesōes de valvas nativas é fato bem comprovado*.

Em apenas um caso, observamos endocardite mural, assestada em lesão endomiocardiofibrótica focal do ventrículo esquerdo, que evolui favoravelmente. Não encontramos relato de caso semelhante, na literatura.

O tratamento cirúrgico consiste na substituição valvar e reparo das lesōes destrutivas teciduais que possam existir.

Remoção de todo tecido envolvido pelo processo infeccioso é essencial ${ }^{11,19}$.

A substituição valvar é realizada pelo uso de próteses da maneira convencional.

Não há consenso unânime sobre se é mais vantajoso o uso de biopróteses, ou de próteses mecânicas, nesta situaçăo 1, 2, 14 .

Por isto, guiamo-nos pelos critérios gerais de escoIha das próteses para cada caso, tendo em conta a idade, sexo, tamanho do anel e da cavidade ventricular.

Foram empregadas 18 biopróteses e 21 próteses mecânicas.
Se houver destruição tecidual abaixo do anel aórtico (abscesso de raíz aórtica), pode ser possivel reparar com uso de pontos ancorados em barras de feltro de Teflon, que se apoiam na borda muscular do septo e no anel da prótese.

Esta manobra visa obter maior segurança na fixação dos pontos, mas tem seu preço em maior possibilidade de causar distúrbios de condução.

Um paciente permaneceu em bloqueio A-V total, necessitando inserção de marcapasso definitivo.

Não tivemos, neste grupo de pacientes, necessidade de utilizar processo mais complexo de reparo, como descrito por vários autores ${ }^{3}$.

Nāo observamos destruiçōes extravalvares, nos casos de localização mitral ou tricúspide.

Em 1 caso, havia comunicação interventricular congênita, que foi corrigida por meio de patch de pericárdio bovino, juntamente com a substituição da valva aórtica.

Outro paciente mostrou acometimento mitro-aortotricúspide e comunicaçāo interventricular adquirida, sendo a substituição valvar acompanhada de fechamento da fistula interventricular com patch de pericárdio.

A variabilidade etiológica, $o$ achado relativamente alto de culturas negativas e o número pequeno de pacientes em cada subgrupo não permitiram correlacionar o agente infeccioso e o prognóstico.

A variação do perfil etiológico de acordo com o tipo de população tratada é fato reconhecido e deve ser levado em conta ao compararem-se séries diversas.

A alta percentagem de culturas negativas em nóssa série $(9 / 32)$ encontra paralelo em outros estudos e é atribuivel a várias causas, tais como uso prévio de antibióticos, endocardites não bacterianas, mas técnicas bacteriológicas e requisitos especiais de crescimento e altos títulos de anticorpos bacterianos circulantes ${ }^{8,}{ }^{15}, 17$.

O perfil sócio-econômico dos pacientes tratados influi, decisivamente, na porcentagem de infectados por bacilos gram-negativos e fungos ${ }^{13}$.

\footnotetext{
- DIAS, A. R.; GRINBERG, M.; MANSUR, A.; VERGINELLI, G.; JATENE, A. D. - Experiência cirúrgica com endocardite infecciosa ativa. Apresentado ao 12: Congresso Nacional de Cirurgia Cardiaca. Rio de Janeiro, 1984.
} 
COSTA, I. A.; FARACO, D. L.; SAllum, F.; PEsarini, A.; Oliveira, E. C.; COSTA, F. D. A.: SOEIRO.

A. B. - Surgical treatment of infective endocarditis in the acute phase: a three-year experience. ReV. Bras. Cir. Cardiovasc., 2(2): 109-114, 1987.

ABSTRACT: Surgical treatment is becoming accepted as the best means of dealing with acute bacterial endocarditis in many clinical settings. The continuing changes in diagnosis, bacteriology and clinical picture of this disease must be accounted for by the surgical teams. Definition of the rules for management of this severe condition has been a matter of concern for us in the last years. From November 1983 to November 1986, $6.7 \%$ of the valvar substitutions in our Service were due to active infection ( 32 of 477 patients). The site of infection was the mitral valve in six patients, aortic valve in 12 patients (one death) mitral and aortic valves in six patients (two deaths), mitral prostheses in two patients (one death) aortic prostheses (three deaths), mitral, aortic and tricuspid valves in one patient (one death) and the wall of the left ventricle in one patient. Age varied from 10 to 56 years $(m=29.2$ years). Seven patients were females and 24 males. All patients were white. Analysis of the pathologic findings allowed us to define three subgroups: In subgroup A, 11 operations were done for simple valvar lesions. All patients left the hospital. Fifteen patients were in the subgroup of extensive valvar or perivalvar lesions, five of which died. Among the six prosthetic infections there were four deaths. The favorable outcome of the patients operated on for simple valvar lesions and the high risk of those who presented extensive tissue destruction or prosthetic infection makes us to prefer immediate surgical treatment if there is no clear response to antibiotics within 24 to 48 hours.

DESCRIPTORS: endocarditis, infective, surgery.

\section{REFERÊNCIAS BIBLIOGRÁFICAS}

1 ARBULU, A. \& ASFAW, I. - Infective endocarditis. In: GLENN, W. D. ed. Thoracic and cardiovascular surgery. Norwalk, Appleton, 1983. p. 1337-1353.

2 CROFT, C.; WOODWARD, W.; ELLIOT, A.; COMMERFORD, P. J.; BARNARD, C. N.; BECK, W. - Analysis of surgical versus medical therapy in active complicated native valve endocarditis. Am. J. Cardiol., 51 (6): 1650-1655, 1983.

3 DANIELSON, G. K.; TITUS, J. L.; DUSHANE, J. W. Successful treatment of aortic valve endocarditis and aortic root abscesses by insertion of prosthetic valve in ascending aorta and placement of by-pass graft to coronary arteries. J. Thorac. Cardiovasc. Surg., 67: 443-449, 1974.

4 GARWEY, G. J. \& NEU, H. C. - Infective endocarditis: an evolving disease. Medicine, 52 (2): 105-127, 1978.

5. JUNG, J. Y.; SAAB, S. B.; ALMOND, C. H. - The case for early surgical treatment of left-sided primary infective endocarditis. J. Thorac. Cardiovasc. Surg., 70 (1): 509-518, 1975.

6 LEĀO, L. E. V.; MOTA, N.; BUFFOLO, E.; GODOI, M.; ANDRADE, J. C. S.; SUCCI, J. E.; SARLE, R.; CAMPOS FILHO, O.; SCHUBSKI, V.; GALLUCCI, C. Substituiçāo valvar na endocardite infecciosa primária. Arq. Bras. Cardiol., 32 (5): 281-288, 1979.
7 LEVITSKI, S.; MAMMANA, R. B.; SILVERMANN, N. A.; WEBER, F.; HIRO, S.; WRIGHT, R. N. - Acute endocarditis in drug addicts: surgical treatment for gram-negative sepsis. Circulation, 66 (Supl. 1): 135-138, 1982.

8 LICHTLEN, P. R.; GAHLK, M. A.; NONNAST-DANIEL, B.; DANIEL, W. G. - Infektiöse Endokarditis. Verh. Dtsch. Ges. Herz u. Kreislaufforsch., 49: 1-19, 1983.

9 MOORE, G. - How to achieve surgical results by really trying. Surg. Gynecol. Obstet., 116 (4): 497-498, 1963. (Editorial)

10 NELSON, R. J.; HARLEY, D. P.; FRENCH, W. J.; BAYER, A. S. - Favorable ten-year experience with valve procedures for active infective endocarditis. J. Thorac. Cardiovasc. Surg., 87 (4): 493-502, 1984.

11 OKIES, J. E.; BRADSHAW, M. W.; WILLIAMS, T. W. Valve replacement in bacterial endocarditis. Chest, 63 (6): 898-904, 1973.

12 OLIVEIRA, P. F.; STIER, H.; HOBACH, F. - Endocardite infecciosa: análise da casuistica do Hospital de Clínicas da UFPR. Arq. Bras. Cardiol., 43 (Supl. 1): 123, 1984. (Resumo)

13 RAPAPORT, E. - The changing role of surgery in the management of infective endocarditis. Circulation, 58 (4): 598-599, 1978.

14 RICHARDSON, J. V.; KARP, R. B.; KIRKLIN, J. W.; DISMUKES, W. E. - Treatment of infective endocarditis: a 10-year comparative analysis. Circulation, 58 (4): 589-597, 1978. 
COSTA. I. A.: FARACO. D. L.: SALlUM, F.: PESARINI. A.: OliveIRA. E. C.: COSTA. F. D. A.: SOEIRO. A. B. - Tratamento cirurgico da endocardite infecciosa na fase aguda: experiència de très anos. Rev. Bras. Cir. Cardiovas. 2(2): 109-114. 1987.

RUDOLPH, W. \& KRANS, F. - Erkennung und Beurteilung der infektiösen Endokarditis. Herz, 8 (5): 241-270. 1983.

WALLACE, A. G.; YOUNG, W. G.; OSTERHART, S. Treatment of acute bacterial endocarditis by valve excision and replacement. Circulation. 31 (3): 450-453, 1965.

17 WIGLE, E. D.: VELLEND, H.; LOVE, K.: LIN, P.; RAKOWISKI. H. - Infective endocarditis in the 1980 's: a continuing diagnostic and therapeutic chalange. In: CHASOV, E. I.; SMIRNOV, V. N.: OGANOV, R. G. eds. Cardiology. New York, Plenum, 1984. p. 727-733.

18 WILSON, W. R.; DANIELSON, G. K.: GIULIANI, E. R.: WASHINGTON, J. A.; JAUMIN, P. M.; GERACI, J. E. - Valve replacement in patients with active infective endocarditis. Circulation, 58 (4): 585-588, 1978.

19 WILSON, W.: DANIELSON, G. K.: GIULIANI, E. R.; WASHINGTON, J. A.; JAUMIN, P. M.; GERARCI, J. E. - Cardiac valve replacement in congestive heart failure due to infective endocarditis. Mayo Clinic. Proc. 54 ( 3 e 4) : 223-226, 1979.

\section{Discussão}

\section{DR. PABLO POMERANTZEFF}

São Paulo, SP

Inicialmente, gostaria de agradecer à organização do Congresso pelo convite e parabenizar o $\mathrm{Dr}$. Iseu Costa, pelo seu trabalho e pelos seus bons resultados. Gostariamos de ressaltar alguns pontos que consideramos de grande interesse. No seu trabalho, o Dr. Iseu coloca que o tratamento cirúrgico na fase agua da endocardite vem-se impondo como o mais efetivo, com o que condordamos totalmente, e também acreditamos que é muito importante definir, com detalhes, quais as circunstâncias clínicas que levam o paciente a necessitar de operaçāo, salientando que o grupo de pacientes que melhoram com o tratamento clínico é, sem dúvida, diferente do grupo de pacientes que melhoram com o tratamento cirúrgico. Acreditamos ser importante destacar, assim como Dr. Iseu o fez, que o que define a doença seriam os diferentes agentes etiológicos, como, por exemplo, Staphylococcus, Streptococcus, gram-negativos, fungos e os di- versos tipos de doentes, com prótese ou sem prótese, e, da interação destes, resulta a sua manifestação clinica. Com relação à oportunidade do tratamento, consideramos que ele não deve ser nem precoce, nem tardio, porém no momento adequado, dependendo da necessidade do doente, levando-se em conta a etiologia, a doença de base e a experiência do Serviço. Um aspecto importante para a discussão é a resposta ao antibiótico em relação à indicação cirúrgica. Nos casos de indicação cirúrgica por razōes hemodinâmicas, sem dúvida não se pode esperar, como mostram os resultados da literatura, mas, quando o problema se relaciona à falha do tratamento etiológico, talvez a indicação não fosse tão urgente. Baumgartner, em 1983, estudando 75 pacientes reoperados por endocardite infecciosa em prótese, relata que a indicação em $87 \%$ dos casos foi a insuficiência cardiaca congestiva, em $15 \%$ dos casos por embolia recorrente e em $4 \%$ dos casos por infecção persistente, sendo a sua mortalidade operatória de $25 \%$ nos casos operados com endocardite ativa e $8 \%$ em endocardite tratada. No Instituto do Coração, de janeiro de 1976 a dezembro de 1984 , foram operados 64 pacientes na fase ativa da endocardite bacteriana, sendo a mortalidade, neste período, de $35 \%$ em pacientes portadores de próteses e $9 \%$ em pacientes com endocardite em valva natural. No trabalho apresentado neste congresso, sobre retroca valvular no Incór, no período de janeiro de 1984 a junho de 1986, a mortalidade em retroca valvular por endocardite bacteriana foi de $11 \%$. No Instituto do Coraçāo, temos utilizado a ecocardiografia intra-operatória, inclusive com contraste, o que pode ser útil para melhor definição em casos de endocardite bacteriana e influir na realização de cirurgias conservadoras na endocardite, como proposto por Gammage, em 1984.

\section{DR. ISEU COSTA \\ (Encerrando)}

Agradeço os comentários do Dr. Pomerantzeff, notando que a sua atitude, e do Incór, que ele representa, é, basicamente, a mesma que defendemos. Creio que todos concordam que o tratamento cirúrgico não deve ser precoce ou tardio, mas sim no momento oportuno. Nossos dados, porém, mostram que a mortalidade aumenta muito nos casos de lesōes complicada e que, infelizmente, o erro mais comum é indicar o tratamento muito tardiamente e não o oposto - isto é - a indicação muito precoce. 